\title{
Do soluble p55 and p75 TNF- $\alpha$ receptor concentrations play a role in women with primary sterility?
}

Joanna Buks ${ }^{1}$, Maciej Wilczak², Paweł Rzymski³ ${ }^{3}$ Tomasz Opala ${ }^{3}$

\author{
1Student Scientific Society of Gynaecology and Obstetrics, Poznan University \\ of Medical Science, Poznan, Poland \\ Institute of Medical Education, Faculty of Health Sciences, Poznan University \\ of Medical Sciences, Poznan, Poland \\ 3Department of Mother's and Child's Health of the Poznan University \\ of Medical Sciences, Faculty of Health Sciences, Poznan University \\ of Medical Sciences, Poznan, Poland
}

Submitted: 29 April 2008

Accepted: 3 July 2008

Arch Med Sci 2010; 6, 2: 264-269

DOI: 10.5114/aoms.2010.13906

Copyright @ 2010 Termedia \& Banach

\section{Abstract}

Introduction: In modern medicine the cause of infertility is believed to be immune mechanism disorders as well as immune over-reactivity. The objective of this thesis is to evaluate the diagnostic usefulness of measuring the concentration of soluble TNF- $\alpha$ receptors $p 55$ and p75 in women with primary infertility.

Material and methods: Examination subjects: 41 female patients with primary sterility in the period January-September 2005. The control group consisted of 13 female patients. For identification of soluble receptors' p55 and p75 TNF- $\alpha$ concentration was used commercial ELISA kits. Quantitative in vitro method of hormone identification in blood serum of plasma (ECLIA) has been used to estimate hormone concentration. Results have been analyzed with Student's $t$-test, Wilcoxon's test, Fisher's exact test and Spearman's test. $P$ value $<0.05$ was considered significant.

Results: There is no significant statistical relation between concentration of soluble p55 and p75 TNF- $\alpha$ receptors and age, BMI index, or length of periods. In the case of soluble p75 TNF- $\alpha$ receptor a statistical correlation with length of period was found $(p=0.004)$. From the statistical point of view, the most advantageous relation was found in the case of p75 TNF- $\alpha$ soluble receptor and thickness of endometrium ( $p=0.007)$ as well as the correlation of $p 55 / p 75$ soluble receptors $(p=0.05)$. The statistical analysis of correlations between TNFR1 and TNFR2 receptors and concentration of hormones FSH, LH, PRL, E2 and testosterone showed no dependence of TNFR1 and TNFR2 receptor concentrations and concentrations of examined hormones. Statistical analysis of relations of TNFR1/TNFR2 receptor concentrations revealed a significant correlation between these receptors and concentration of LH $(p=0.05)$.

Conclusions: The correlation between endometrium thickness, size of dominating vesicle and concentration of LH compared to concentrations of soluble TNF- $\alpha$ receptors $\mathrm{p} 55$ and $\mathrm{p} 75$ and their ratio might condition the time of survival of the vesicle or lead to excessive expression of its atresion-leading conditions.

Key words: tumour necrosis factor, immune mechanism, primary sterility, soluble TNF- $\alpha$ receptor $p 55$, soluble TNF- $\alpha$ receptor p75.

\author{
Corresponding author: \\ Prof. Maciej Wilczak \\ Institute of Medical \\ Education \\ Faculty of Health Sciences \\ Poznan University \\ of Medical Sciences \\ Dabrowskiego Street N 79 \\ 60-529 Poznan, Poland \\ Phone: +48 618546900 \\ Fax: +48 618546901 \\ E-mail: \\ mwil@gpsk.ump.edu.pl
}




\section{Introduction}

Infertility is a significant epidemiological problem that is particularly prominent in developed countries. In Poland, according to epidemiological data, infertility or inability to deliver occurs in about 1 million (18-20\%) married couples [1].

The sterility problem has been considered by WHO (World Health Organisation) as a social disorder [2].

While fertility depends on many organic, hormonal and psychological factors and on male sterility, modern medicine tends to seek reasons in failures within mechanisms of the immune system as well as its hyperactivity [1].

The aetiology of sterility with its basis in the immune system is still not well understood. Two soluble receptors, p55 (TNFR1, CD 120a, p55a, 55-kDa protein, TNFRSF1, type 1 TNF- $\alpha$ ) and p75 (TNFR2, CD 120b, p75 $\alpha, 75-k$ Da protein, TNFRSF1B, type 2 TNF- $\alpha$ ), are likely to be involved in the pathomechanisms of sterility. These two receptors seem to be present in most human cells and they interact with TNF- $\alpha$ (tumour necrosis factor $\alpha$, cachectin), which results in signal transduction and expression of NF-B and c-Jun. These two factors are in turn responsible for expression of genes responsible for growth and death of a cell, cancer formation, the immune response, cellular stress and inflammation. Molecules from the TNF subfamily are expressed in almost every cell and participate in most regulatory processes in the human body [3-11].

Recently it is thought that p55 TNF- $\alpha$ receptor is responsible for inducing apoptosis, whereas p75 TNF- $\alpha$ stimulation is involved in cellular proliferation, and there have been many antagonistic models of the two receptors reported in the literature. The two proteins differ in mass, glycosylation level, affinity for TNF and inner-cell domain structure. Due to these differences, signalling by the two receptors provides different information to a cell. The inner-cell part of the p55 TNF- $\alpha$ receptor consists of a 70 amino acid long domain, known as the death domain (DD), which can induce apoptosis: Apo-1/ Fas (CD95), DR2, DR3, TRAIL-R1 (DR-4), TRAIL-RZ (DR5), DR6. TNF receptors are present on almost every cell - TNFR2 is found in leukocytes and endothelial cells, whereas TNFR2 is present in endodermal cells. Lymphocytes, fibroblasts and endothelial cells have both of the TNF receptors on their surfaces. Both are also present in serum, which results in absorption of TNF from blood and decrease of its biological effect [6, 12-14].

The direct action of various TNFs on the human immune system is known to be due to their induced release from lymphocytes (such as IFN- $\gamma$ ) and from macrophages. The latter release IL-1,
IL-6, GM-CSF, G-CSF, M-CSF, PDGF, NGF, EGF and PAF (platelet activating factor), IFN- $\beta$, and many products of the arachidic acid cycle. It has been observed that GM-CSF is often present within oocytes which have not been fertilized. Activation of macrophages and a few other cells by increased levels of GM-CSF within oocytes that fail to develop properly suggests a possible relationship between the immune system and the endocrine system with the involvement of cytokines. It was shown that increased GM-CSF concentration remains in correlation with female infertility, due to macrophage activation and decreased capability of oocytes to be fertilized. GM-CSF can also influence the antigen presentation by male cells and the immune response of female cells and of tissues during transplantation. TNF also induces expression of MHC type I and type II proteins [13, 15].

According to the literature, proinflammatory cytokines (IL-1 $\beta$, IFN- $\gamma$, TNF- $\alpha$ ) participate in autocrine and paracrine regulation of growth and differentiation of the placenta, implantation of the fertilised egg cell and the early stage of embryogenesis $[1,16,17]$.

Lack of cytokines with Th2 activity or too high amounts of cytokines of type Th1 disrupts the proper implantation process. The hormonal system, cooperating with the immune system, has a significant role in vesicular development (their recruitment, selection and domination) and later in fertilization and implantation. Hormonal factors that regulate ovarian vesicular development consist of: gonadotrophins (LH, FSH), prolactin, ovarian steroids (oestradiol, androgens, progesterone), ovarian peptides and proteins (inhibin, activin, follistatin) and a spectrum of insulin-like growth factors (IGF). Research has also shown the involvement of growth factors such as: epithelial growth factor (EGF), transforming growth factor $\alpha$ (TGF- $\alpha$ ), plateletderived growth factor (PDGF), fibroblast growth factor (FGF), transforming growth factor $\beta$ (TGF- $\beta$ ), interleukin, and vascular endothelial growth factor (VEGF) $[15,18]$.

There is a whole array of factors that influence survival of an egg cell, among them IGF-1, which is produced by granulocytes and which stimulates vascular cells to produce EGF/TGF, which halts apoptosis of granulocytes. FSH acts on vascular cells to increase the synthesis of TGF/EFG- $\alpha$ and release factors that stimulate vascular cells to produce TGF/EFG- $\alpha$ as well. IGF-1, produced by granulocytes, also stimulates vascular cells, which leads to an increase in EGF/TGF concentrations. These factors, in a paracrine fashion, act on granulocytes, inhibiting their apoptosis [15, 19-22].

The aim of this study was to evaluate the concentration of soluble p55 and p75 TNF- $\alpha$ receptors in women with primary sterility. 


\section{Material and methods}

Studies were carried out on 41 examined female patients (age 17 to 42 ) with primary sterility, under treatment in the Department of Mother's and Child's Health of Poznan University of Medical Sciences in the period January-September 2005. The materials were collected during regular, diagnostic examinations of these patients, after they had been assessed for ovulation and in parallel with hormonal examinations. Because of the small control group, there were no subgroups formed. The control group consisted of 13 female patients who had checked in for routine control examinations. Eight of these women had already delivered once before and five of them had delivered twice. Patients, upon arrival at the hospital, had their reproductive organs examined with Aloka SSD 5000 with vaginal probe detector ultrasound with a frequency of $7.5 \mathrm{MHz}$. Blood samples were taken from the patients (initially for routine, hormonal studies carried out in parallel to investigate sterility - described later on), centrifuged and the serum frozen at $-70^{\circ} \mathrm{C}$. A commercially available ELISA kit (enzyme-linked immunosorbent assay) was used to label p55 and p75 TNF- $\alpha$ receptors. TNF- $\alpha-R 1$ and TNF- $\alpha-R 2$ were assayed using Quantikine (R\&D Systems, USA) with sensitivity 0.77 and $1.0 \mathrm{pg} / \mathrm{ml}$ respectively. Extinction coefficient readouts were taken at $450 \mathrm{~nm}$ with BioTek Instruments, Inc. EL x 808, Ultra Microplate Reader (620-650 nm correction). FSH, LH, E2, PRL and testosterone concentrations were determined using an Elecsys analyser from Roche Diagnostic. Concentrations of various plasma and serum hormones were determined using ECLIA (electrochemiluminescence immunoassay).

Statistical analyses were carried out using SigmaStat 3.1 (Systat Inc, USA). Results are presented as mean values \pm standard deviation (SD). Wilcoxon test was used to compare differences, since there was no normal distribution shown in Kolmogorov-Smirnov test. Occurrence frequencies were characterised with a Fisher's exact test. Value correlations were analysed with Spearman's test. Values with $p<0.05$ were considered as statistically significant. The experiments were approved by the Medical University Bioethical Committee.

\section{Results}

Mean age and BMI (body mass index) values indicate no difference between the control group and the study subjects - see Table I. Wilcoxon's test showed no statistically significant difference between mean age, BMI and the length of the menstrual cycle among patients from the analysed groups.

Results from the statistical analysis (Table II) show no significant statistical relationship between p55 and p75 TNF- $\alpha$ receptor concentrations, mean age, BMI, length of menstrual cycle and duration of menstruation. Therefore, there is no correlation between these parameters and the concentration of p55 and p75 TNF- $\alpha$ receptors.

In the case of soluble p75 TNF- $\alpha$ receptor, it was shown to correlate with the frequency of occurrence of the cycles $(p=0.004)$. Similar tendencies were

Table I. Comparison of various parameters obtained from patients with primary sterility and the control group

\begin{tabular}{|lccc|}
\hline Parameters & Sterility $(n=28)$ & Control $(n=13)$ & Wilcoxon test $p$ \\
\hline Age [year] & $28.0 \pm 4.1$ & $30.4 \pm 8.6$ & 0.49 \\
\hline BMI [kg/m²] & $21.5 \pm 2.7$ & $21.6 \pm 3.0$ & 0.91 \\
\hline Length of menstrual cycle [day] & $32.4 \pm 9.4$ & $28.7 \pm 1.3$ & 0.74 \\
\hline Regularity of cycle [\%] & $21 / 28$ & $12 / 13$ & $0.06^{*}$ \\
\hline Mean duration of bleeding [day] & $5.6 \pm 1.0$ & $6.4 \pm 2.6$ & 0.46 \\
\hline sICAM-1 [ng/ml] & $200.1 \pm 60.7$ & $210.0 \pm 63.7$ & 0.64 \\
\hline FSH [mlU/ml] & $7.96 \pm 5.84$ & $10.26 \pm 12.47$ & 0.28 \\
\hline LH [mlU/ml] & $14.74 \pm 15.60$ & $10.43 \pm 9.04$ & 0.39 \\
\hline Oestradiol [pg/ml] & $142.8 \pm 129.9$ & $135.6 \pm 123.1$ & 0.84 \\
\hline Prolactin [ng/ml] & $22.7 \pm 13.4$ & $29.9 \pm 50.8$ & 0.21 \\
\hline Testosterone [ng/ml] & $0.47 \pm 0.16$ & $0.48 \pm 0.21$ & 0.93 \\
\hline p55 [pg/ml] & $1489 \pm 234$ & $1397 \pm 180$ & 0.22 \\
\hline p75 [pg/ml] & $3889 \pm 117$ & $2748 \pm 516$ & $<0.001$ \\
\hline p55/p75 & $0.40 \pm 0.08$ & $0.52 \pm 0.06$ & $<0.001$ \\
\hline
\end{tabular}

*Fisher's exact test 
Table II. Correlations (RS) between various parameters obtained from studies on women with primary sterility and the concentration of $\mathrm{p} 55$ and $\mathrm{p} 75$ TNF- $\alpha$ receptors as well as their ratios

\begin{tabular}{|lccc|}
\hline Parameter & Receptor $\mathrm{p55}$ & Receptor $\mathrm{p75}$ & $\mathrm{p55} / \mathrm{p75}$ \\
\hline Age [year] & $-0.20, p=0.23$ & $0.01, p=0.93$ & $0.01, p=0.93$ \\
\hline BMI [kg/m²] & $0.06, p=0.67$ & $0.04, p=0.77$ & $-0.01, p=0.92$ \\
\hline Labours [number] & $-0.13, p=0.42$ & $-0.36, p=0.02$ & $0.38, p=0.01$ \\
\hline Abortions [number] & $-0.34, p=0.03$ & $-0.06, p=0.69$ & $-0.01, p=0.95$ \\
\hline Regular of menstruation cycle [\%] & $-0.05, p=0.72$ & $-0.31, p=0.04$ & $0.37, p=0.01$ \\
\hline Length of menstrual cycle [day] & $0.29, p=0.08$ & $0.27, p=0.10$ & $-0.20, p=0.24$ \\
\hline Duration of menstrual bleeding [day] & $-0.06, p=0.73$ & $0.09, p=0.60$ & $-0.23, p=0.21$ \\
\hline FSH [mIU/ml] & $0.13, p=0.39$ & $0.14, p=0.35$ & $-0.10, p=0.50$ \\
\hline LH [mIU/ml] & $0.02, p=0.88$ & $0.22, p=0.16$ & $-0.30, p=0.05$ \\
\hline E2 [pg/ml] & $-0.02, p=0.90$ & $-0.07, p=0.63$ & $0.07, p=0.65$ \\
\hline PRL [ng/ml] & $-0.07, p=0.66$ & $0.08, p=0.60$ & $-0.11, p=0.45$ \\
\hline Testosterone [ng/ml] & $0.07, p=0.67$ & $-0.07, p=0.66$ & $0.02, p=0.98$ \\
\hline slCAM-1 [ng/ml] & $0.19, p=0.23$ & $0.05, p=0.72$ & $0.0, p=0.98$ \\
\hline Thickness of endometrium & $0.18, p=0.52$ & $0.67, p=0.007$ & $-0.52, p=0.05$ \\
\hline in US Examination [mm] & & & $-0.43, p=0.04$ \\
\hline Diameter of follicle [mm] & $-0.20, p=0.37$ & $0.23, p=0.28$ & \\
\hline
\end{tabular}

obtained when comparing the p55/p75 ratios $(p=0.01)$. The most favourable correlation was found between concentration of soluble p75 TNF- $\alpha$ receptor, thickness of endometrium ( $p=0.007)$ and the ratio of $p 55 / p 75$ receptor concentrations $(p=0.05)$. Similar values were obtained for $p 55 / p 75$ ratio and the size of growth ovarian vesicular $(p=0.04)$.

Statistical analysis of the correlations between TNFR1 and TNFR2 receptors and FSH, LH, PRL, E2, and testosterone concentrations showed no relationships (Table II).

A significant relationship was found between the TNFR1/TNFR2 concentration ratio and the concentration of $\mathrm{LH}(p=0.05)$.

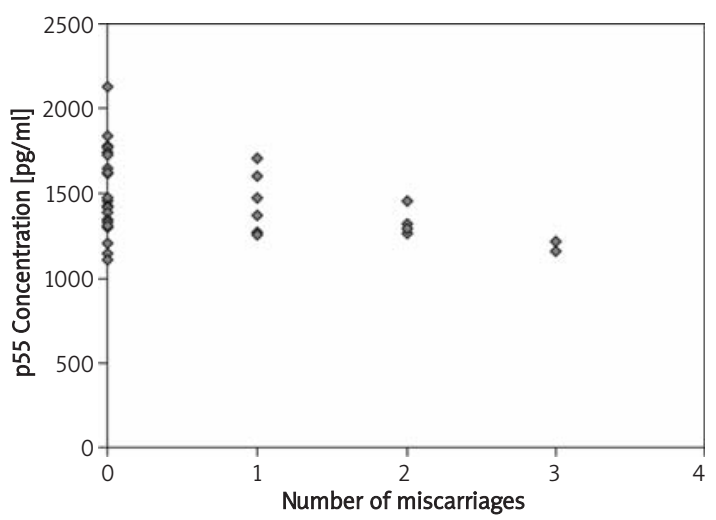

Figure 1. Relationship between the number of miscarriages and the concentration of p55 TNF- $\alpha$ receptor.

\section{Discussion}

Many clinical experiments and observations have shown that TNF- $\alpha$ has immunoregulatory properties, influencing directly and indirectly the processes within the immune system $[1,6,13$, 23, 24].

According to Tchórzewski [25] even the smallest concentrations of TNF- $\alpha$ can increase the immune response to antigens on $T$ lymphocytes. This cytokine also stimulates phagocytic processes, especially oxidative metabolism and neutrophil aggregation, and increases the expression of integrin (CD11/CD18).

According to Emdo and Baird [26] TNF- $\alpha$ takes part in inhibition of 17- $\alpha$-hydroxylase/17,20-lyase,

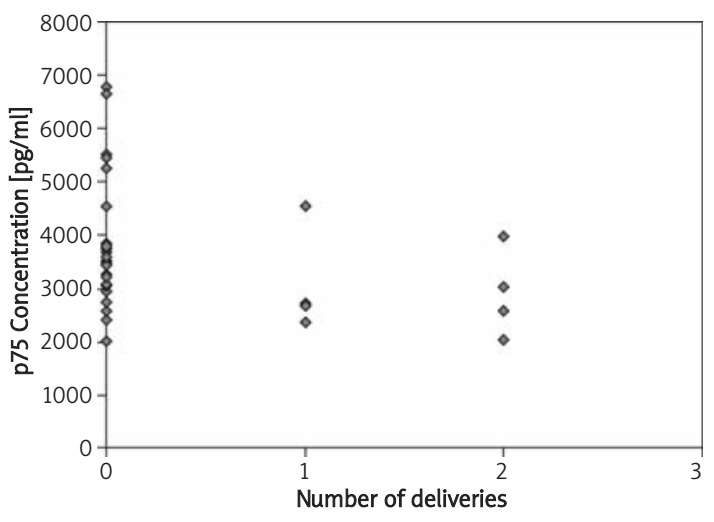

Figure 2. Relationship between the number of deliveries and the concentration of p75 TNF- $\alpha$ receptor. 


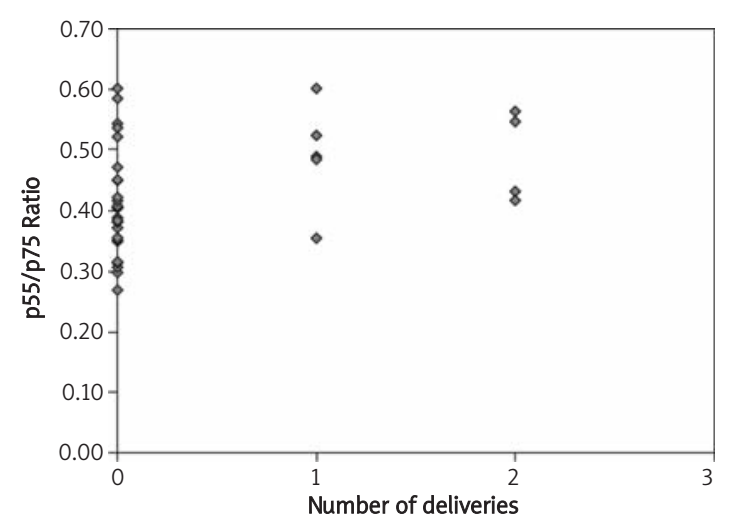

Figure 3. Relationship between the number of deliveries and the ratio of p55/p75 concentrations

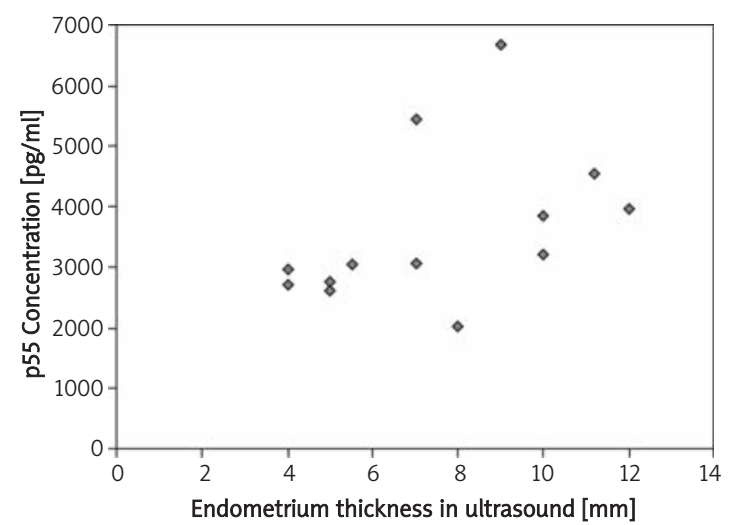

Figure 5. Relationship between thickness of endometrium (USG values) and the concentration of p75 TNF- $\alpha$ receptor

which influences ovarian activity. An environment rich in androgens influences the procavity follicle, inhibiting the activity of aromatase. The follicle becomes androgenic, and finally arthritic. The appropriate response of endometrium to the release of progesterone in the luteal phase depends on the activity of oestrogens and the level of their aromaticity. Their changes are important for correct ovulation, fertilization, and egg cell implantation.

Our studies support the idea that soluble p55 and $\mathrm{p} 75$ TNF- $\alpha$ receptors play a crucial role in regulation of foetal development, the immune response and hormone homeostasis. Their increased concentrations in blood serum can lead to ovulation disorders, implantation disorders and, most importantly, to sterility in women. Our results have provided evidence that supports these speculations. We have found statistically significant correlations between thickness of endometrium, size of the growth ovarian vesicular and the concentration of soluble p75 TNF- $\alpha$ receptor as well as the $\mathrm{p} 55 / \mathrm{p} 75$ TNF- $\alpha$ receptor ratio.

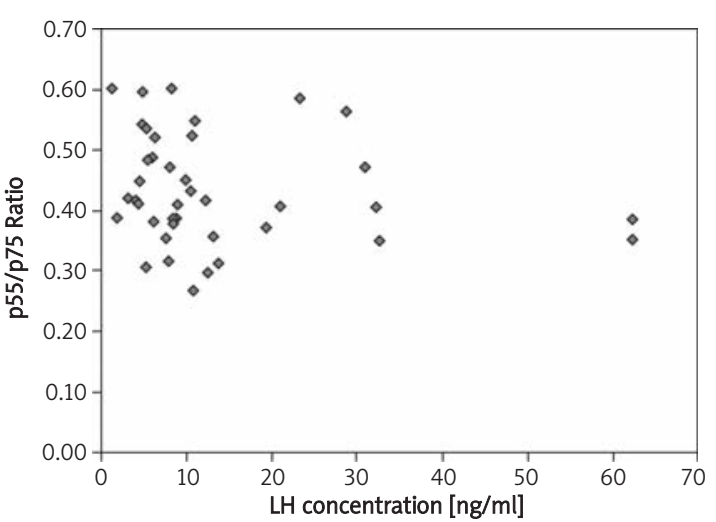

Figure 4. Relationship between LH concentration and the ratio of $\mathrm{p} 55 / \mathrm{p} 75$ concentrations

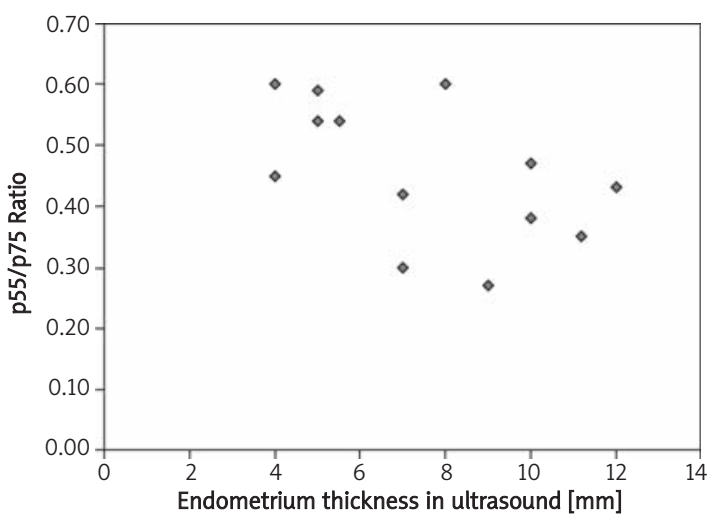

Figure 6. Relationship between thickness of endometrium (USG values) and the ratio of p55/p75 concentrations

According to Weinberg [27], increased concentration of GM-CSF can lead to infertility, due to macrophage activation. The same mechanism takes place in the liquid of ovulation vesicular, which as a result can lead to decreased ability of oocytes to become fertilized.

Weinberg also claims that activation of macrophages (or some other cells) leads to increased release of GM-CSF and to oocyte maturation disorders, caused by TNF- $\alpha$ activation. Our research shows correlations between LH release, fertility and soluble p55/p75 TNF- $\alpha$ receptor ratios.

According to Putowski [28], only endometrium appropriately prepared in the luteal phase is capable of accepting a developing blastocyst and only during a normal cycle. He claims that the microenvironment of the endometrium (including the immunocompetent cells) mostly influences the hormonal proteins, growth factors, lymphokines, prostaglandin and PAF. Some other resources show that PAF release has a direct impact on TNF- $\alpha$, which might be the cause of infertility $[1,26,29]$. 
Our research provides evidence for the influence of soluble p55 and p75 TNF- $\alpha$ receptors on fertility disorders in women. Correlations between thickness of endometrium, size of the dominant follicle, $\mathrm{LH}$ concentration and concentrations of these two receptors (as well as their ratio) might determine the survival of vascular or lead to hyperexpression of factors that lead to atresia.

Despite the fact that our research covers only a small group of patients and that the results require extended and randomised clinical studies, they may contribute to our understanding of the complex problem of aetiopathogenesis of infertility in women.

In conclusion:

1) we estimated correlations between thickness of endometrium, size of the dominant follicle, $\mathrm{LH}$ concentration and the concentrations of soluble p55 and p75 TNF- $\alpha$ receptors and their ratio,

2) results from the statistical analysis show no significant statistical relationship between p55 and $\mathrm{p} 75 \mathrm{TNF}-\alpha$ receptor concentrations, mean age, BMI, length of menstrual cycle or time of menstruation,

3) statistical analysis of the relations of TNFR1/TNFR2 receptor concentrations shows a significant correlation between these receptors and concentration of LH $(p=0.05)$.

\section{Acknowledgments}

This scientific research was financed with grant number: 501-01-4412525-08454.

\section{References}

1. Radwan J. Infertility and adjunct reproduction. TERMEDIA 2004.

2. Spaczynski M. Progress in gynecology and obstetrics. ADAMED 2006; 369-72.

3. Bazzoni F, Beutler B. The tumor necrosis factor ligand and receptor families. N Eng J Med 1996; 334: 1717-24.

4. Brockhaus M, Schoenfeld HJ, Schlaeger EJ, Hunziker W, Lesslauer W, Loetscher H. Indentification of two types of tumor necrosis factor receptors on human cell lines by monoclonal antibodies. Proc Natl Acad Sci U S A 1990; 87: 3127-31.

5. Chen G, Goeddel DV. TNFR1 signaling: a beautiful pathway. Science 2002; 296: 1634-5.

6. Golab J, Jakobisiak M, Lasek W. Immunology. PWN 2002; 236-46.

7. Medvedev AE, Espevik T, Ranges T, Sundan A. Distinct roles of the two tumor necrosis factor (TNF) receptors in modulating TNF and lymphotoxin alpha effects. J Biol Chem 1996; 271: 9778-84.

8. Maymon E, Ghezzi F, Edwin SS, et al. The tumor necrosis factor alpha and its soluble receptor profile in term and preterm parturition. Am J Obstet Gynecol 1999; 181: 1142-8.

9. Opala T, Rzymski P, Wilczak M, Wozniak J, Drews K, Sajdak S. Evaluation of CA-125, sICAM-1, soluble receptors TNFalpha p55 and p75 in prediction of optimal primary surgical treatment in patients with ovarian cancer. Gynecol Obstet Rev 2004; 4: 71-6.
10. Rzymski P. Tumor necrosis factor alpha receptors $\mathrm{p} 55$ and p75 and ovarian cancer- state- of- the- art research and clinical implications. Arch Med Sci 2005; 1: 3-7.

11. Sancho-Tello M, Marcinkiewicz JL, Justice WM, Kimler Teranova PF, Hunter VJ. Reduction of tumor necrosis factor-alpha bioactivity by a human ovarian epithelial cancer cell line in vitro. Am J Obstet Gynecol 1995; 173: 1470-7.

12. Onsrud M, Shabana A, Austgulen R, Nustad K. Comparison between soluble tumor necrosis factor receptors and CA125 in peritoneal fluids as a marker for epithelia ovarian cancer. Gynecol Oncol 1995; 57: 183-7.

13. Robak T. Biology and pharmacology of cytokines. PWN 1995; 24: 255-8.

14. Rzymski P, Opala T, Wilczak M, Wozniak J, Sajdak S. Serum tumor necrosis factor alpha p55/p75 ratio and ovarian cancer detection. Int J Gynecol Obstet 2005; 88: 292-8.

15. Gavrieli Y, Sherman Y, Ben-Sasson SA. Indentification of programmed cell death in situ via specific labeling for nuclear DNA fragmentation. J Cell Biol 1992; 119: 493-501.

16. Skrzypczak J, Puk E, Kurpisz M. May GM-CSF influence the ability to fertilize oocytes? Pol Gynecol 1999; 6: 433-9.

17. Tartakovsky B. CSF1 induces resorption of embryos in mice. Ol Lett 1989; 23: 65-9.

18. Tilly JL. Ovarian folicullar atresia: a model to study the mechanism of physiological cell death. Endocr J 1994; 1: 67-27.

19. Hsueh AJ, Billig H, Tsafriri A. Ovarian-follicle atresia: a hormonally controlled apoptotic process. Endocr Rev 1994; 15: 707-24.

20. Hughes FM, Gorospe WC. Biochemical indentification of apoptosis (programed cell death) in granulosa cell: evidence for a potential mechanism underlying folicullar atresia. Endocrinology 1991; 129: 2415-22.

21. Tabibzadeh S. Contribution of cytokines to apoptosis in the ovary and in endometrium. A current Overview Proceedings of the 15th World Congress of Fertility and Sterility, Montpelier, France 17-22 Sept. Fertil Steril 1995; 32: 237.

22. Zolti M, Ben-Rafael Z, Meriom R. Cytokine involvment in oocytes and early embryos. Fertil Steril 1991; 56: 265-72.

23. Fukaya T, Sugawara J, Yoshida H, Yajima A. The role of macrophage colony-stimulating factor in the peritoneal fluid in infertile patients with endometriosis. Tohoku J Exp Med 1994; 172: 221-6.

24. Sajdak S, Skrzypczak J. Endometrium. Modulation. Evolution. Blackhorse 2004; 59-60.

25. Tchorzewski H. Inflammation. Physiopathology and clinic. Medpress, Warszawa 1998; 13-38.

26. Emoto N, Baird A. The effect of tumor necrosis factor/cachectin on follicle stimulating hormone - induced aromatase activity in cultured rat granulosa cells. Biochem Biophys Res Commun 1988; 153: 792-8.

27. Weinberg J, Haney A, Xu F. Peritoneal fluid and plasma levels of human macrophage colony-stimulating factor in relation to peritoneal fluid macrophage content. Blood 1991; 78: 513-6.

28. Putowski L, Darmochwal-Kolarz D. Endometrium changes during implantation. Sajdak S, Skrzypczak J. Endometrium. Modulation. Evolution. Blackhorse 2004; 6: 53-6.

29. Slomko Z, Drews K. Perinatal inflammation. PTMP 2001; 3: 52-62. 